\title{
Key components of the delirium syndrome and mortality: greater impact of acute change and disorganised thinking in a prospective cohort study
}

\author{
R. A. Diwell ${ }^{1}$, D.H. Davis ${ }^{2}$, V. Vickerstaff ${ }^{1,3}$ and E. L. Sampson ${ }^{1,4^{*}}$ (D
}

\begin{abstract}
Background: Delirium increases the risk of mortality during an acute hospital admission. Full syndromal delirium (FSD) is associated with greatest risk and subsyndromal delirium (SSD) is associated with intermediate risk, compared to patients with no delirium - suggesting a dose-response relationship. It is not clear how individual diagnostic symptoms of delirium influence the association with mortality. Our objectives were to measure the prevalence of FSD and SSD, and assess the effect that FSD, SSD and individual symptoms of delirium (from the Confusion Assessment Method-short version (s-CAM)) have on mortality rates.
\end{abstract}

Methods: Exploratory analysis of a prospective cohort (aged $\geq 70$ years) with acute (unplanned) medical admission (4/6/2007-4/11/2007). The outcome was mortality (data censored 6/10/2011). The principal exposures were FSD and SSD compared to no delirium (as measured by the CAM), along with individual delirium symptoms on the CAM. Cox regression was used to estimate the impact FSD and SSD and individual CAM items had on mortality.

Results: The cohort $(n=610)$ mean age was 83 (SD 7); 59\% were female. On admission, 11\% had FSD and 33\% had SSD. Of the key diagnostic symptoms for delirium, 17\% acute onset, 19\% inattention, 17\% disorganised thinking and $17 \%$ altered level of consciousness. Unadjusted analysis found FSD had an increased hazard ratio (HR) of 2.31 (95\% Cl 1.71, 3.12), for SSD the HR was $1.26(1.00,1.59)$. Adjusted analysis remained significant for FSD $(1.5595 \% \mathrm{Cl} 1.10,2.18)$ but nonsignificant for SSD ( $\mathrm{HR}=0.9295 \% \mathrm{Cl} 0.70,1.19)$. Two CAM items were significantly associated with mortality following adjustment: acute onset and disorganised thinking.

Conclusion: We observed a dose-response relationship between mortality and delirium, FSD had the greatest risk and SSD having intermediate risk. The CAM items "acute-onset" and "disorganised thinking" drove the associations observed. Clinically, this highlights the necessity of identifying individual symptoms of delirium.

Keywords: delirium, full syndromal delirium, subsyndromal delirium, mortality, Confusion Assessment Method, prospective cohort, acute hospital

\footnotetext{
* Correspondence: e.sampson@ucl.ac.uk

${ }^{1}$ Marie Curie Palliative Care Research Department, Division of Psychiatry,

Faculty of Brain Sciences, University College London, Gower Street, London WC1E 6BT, UK

${ }^{4}$ Barnet Enfield and Haringey Mental Health Trust Liaison Psychiatry Team, North Middlesex University Hospital, London N18 1QX, UK

Full list of author information is available at the end of the article
} 


\section{Background}

Delirium is an acute neuropsychiatric syndrome affecting around $25 \%$ of general hospital patients aged over 65 years [1-4]. It is characterised by acute onset and fluctuating course of disturbed attention, consciousness, orientation, memory, arousal and, behaviour, and alterations in perception and sleep cycle [5].

The aetiology of delirium is complex and multifactorial, including causes such as infection, sleep deprivation, pain, specific organ failures and metabolic disturbances [1, 6-8]. Each individual's threshold for delirium differs depending on predisposing risk factors such as age and frailty.

Many operational definitions exist for delirium, including formal classifications in the Diagnostic and Statistical Manual of Mental Disorders (DSM) and algorithms such as the Confusion Assessment Method (CAM) [9]. Intermediate states, subsyndromal delirium (SSD), can be defined where individuals have symptoms of delirium but insufficient to meet the criteria for full syndromal delirium (FSD) [10].

FSD is associated with a number of poor outcomes, such as longer hospital stays, increased risk of posthospital institutionalisation post-discharge, and accelerated cognitive decline $[3,8,11-14]$. FSD carries its own risk of death, independent of an individual's exposure to established risk factors [3, 15-18]. The literature on SSD and adverse outcomes is less conclusive, partly because of variable definitions of SSD in relation to symptom clusters and/or severity $[10,19,20]$.

It is possible that a dose-response relationship between FSD and mortality operates, such that SSD carries intermediate risk [21]. However, this has often not been systematically evaluated in the same cohort, using standardised definitions and maximally adjusting for a wide range of acute and chronic health factors [19]. It is also not clear whether specific delirium symptoms drive the mortality relationship observed. In particular, no studies have estimated mortality rates associated with individual diagnostic items from rating scales such as the CAM.

Our objectives were to: (1) examine the prevalence of FSD and SSD in a representative cohort of older acute hospital inpatients over the age of 70 years; (2) estimate the impact of FSD and SSD (as measured by the short CAM (s-CAM) on admission) on mortality rates and (3) assess the impact individual key diagnostic items on the $\mathrm{s}$-CAM have on this relationship.

\section{Methods}

\section{Design}

We undertook an exploratory retrospective analysis of data collected on a cohort of older people with acute medical illness admitted into hospital between 4/6/2007 to 4/ $11 / 2007$. Characteristics of the cohort have been described previously [22]. In brief, participants were eligible for inclusion if they were: $\geq 70$ years old with an unplanned medical admission who were admitted $>48 \mathrm{~h}$. All clinical assessments were conducted by psychiatrists within $72 \mathrm{~h}$ of admission. Participants who lacked English language skills necessary to complete basic cognitive assessments were excluded. We sought verbal consent from participants or, if they lacked capacity to consent, verbal assent from their carers. The study involved the collection of routine clinical data that has subsequently been fully anonymised. The findings of these assessments were documented on the medical notes so that clinical teams could act on them if they wished. The exclusion of patients unable to give written informed consent or those without a relative to give assent for their participation may have caused selection bias, excluding the patient population we wished to study. The study and its verbal consent procedure was approved by the Royal Free Hospital NHS Trust Ethics Committee (06/Q0501/31).

\section{Outcome}

Mortality was flagged by the UK Office for National Statistics (ONS) (mortality data censored 6/10/2011).

\section{Main exposures \\ Delirium}

Participants were assessed using the Confusion Assessment Method, short version (s-CAM), which details the following delirium features: (1) acute onset, (2) inattention, (3) disorganised thinking, (4) altered level of consciousness [23]. The s-CAM has high sensitivity of $>94 \%$ and specificity $>90 \%$ for the detection of delirium and accurately distinguishes between delirium and dementia [24]. FSD was defined as persons demonstrating abnormalities in features $1+2+(3$ or 4$)$. SSD was defined as having one or more s-CAM symptoms, but not fulfilling criteria for FSD. All participants without symptoms of FSD or SSD were defined as 'no delirium'.

\section{Covariates}

Demographic data (age, sex, place of residence, ethnic origin and marital status) was collected from hospital records. Other assessments included the Charlson Co-morbidity Index [25, 26], Waterlow Scale [27] and a modified version of the Acute Physiology and Chronic Health Evaluation (APACHE II) [28-30] (omitting the arterial blood gas). Severity of functional impairment prior to hospital admission was gathered from next of kin or other carers using the Functional Assessment Staging Scale (FAST) [31].

\section{Data analysis}

Differences in categorical and continuous variables according to delirium status were assessed using chisquare, ANOVA and Kruskal Wallis tests as appropriate. Continuous variables with skewed data (CCI 
and APACHE II scores) were categorised into standard quartiles for the final analysis.

Survival estimates for FSD, SSD and no delirium were compared using Kaplan-Meier curves and log-rank tests. Cox regression was used to examine the relationship between FSD, SSD and no delirium with mortality risk, sequentially adjusting for relevant confounders in a multivariable model. Finally, the relationship between each CAM criterion and mortality was estimated in the whole cohort, irrespective of syndromal status.

Proportional hazard assumptions were met for all Cox regression analyses, confirmed by Schoenfeld Residuals $\geq 0.05$. Finally, candidate prediction models were compared using Harrell's c statistics. Data were analysed using STATA version 12 .

\section{Results}

\section{Study population}

A total of 785 participants were recruited, of these, 75 participants had missing data and were excluded, leaving 710 participants assessed using the s-CAM at the time of admission. Exclusions occurred due to: incomplete/ missing data $(n=32,(5 \%)$, being too ill $(n=18,(2 \%)$, untraceable $(n=2,(1 \%)$, unable to speak English sufficiently $(n=25,(3 \%)$, refusal to participate $(n=23,(3 \%)$.
Therefore, 610 (86\%) participants from the original sample were included (Fig. 1).

Mean age was 83 (sd 7) and over half were female (59\%). A majority of the participants lived in their home (71\%) and were of White British origin (70\%) (Table 1).

A total of 69 (11\%) participants had FSD, 202 (33\%) had SSD and 339 (56\%) had no delirium. The diagnostic symptom inattention had slightly higher prevalence (19\%) compared to acute onset, disorganised thinking and altered level of consciousness (17\%). Median CCI score was 2 (IQR 3) and APACHE II score was 11 (IQR 4), and the mean Waterlow score was 13 (6) (Table 1).

Prevalence of FSD and SSD increased with age, though there was no association with gender. FSD and SSD became more prevalent as age increased. Participants with FSD and SSD were more likely to live in nursing or sheltered accommodation. There was an overall higher prevalence of having a pre-existing dementia diagnosis, higher Waterlow scores, higher APACHE II scores and greater length of hospital stay.

Kaplan-Meier curves showed delirium was associated with reduced survival and that participants with FSD had greatest reduction in survival estimates compared to participants with no symptoms, and SSD had intermediate reduction $(<0.001)$ (Fig. 2). FSD had

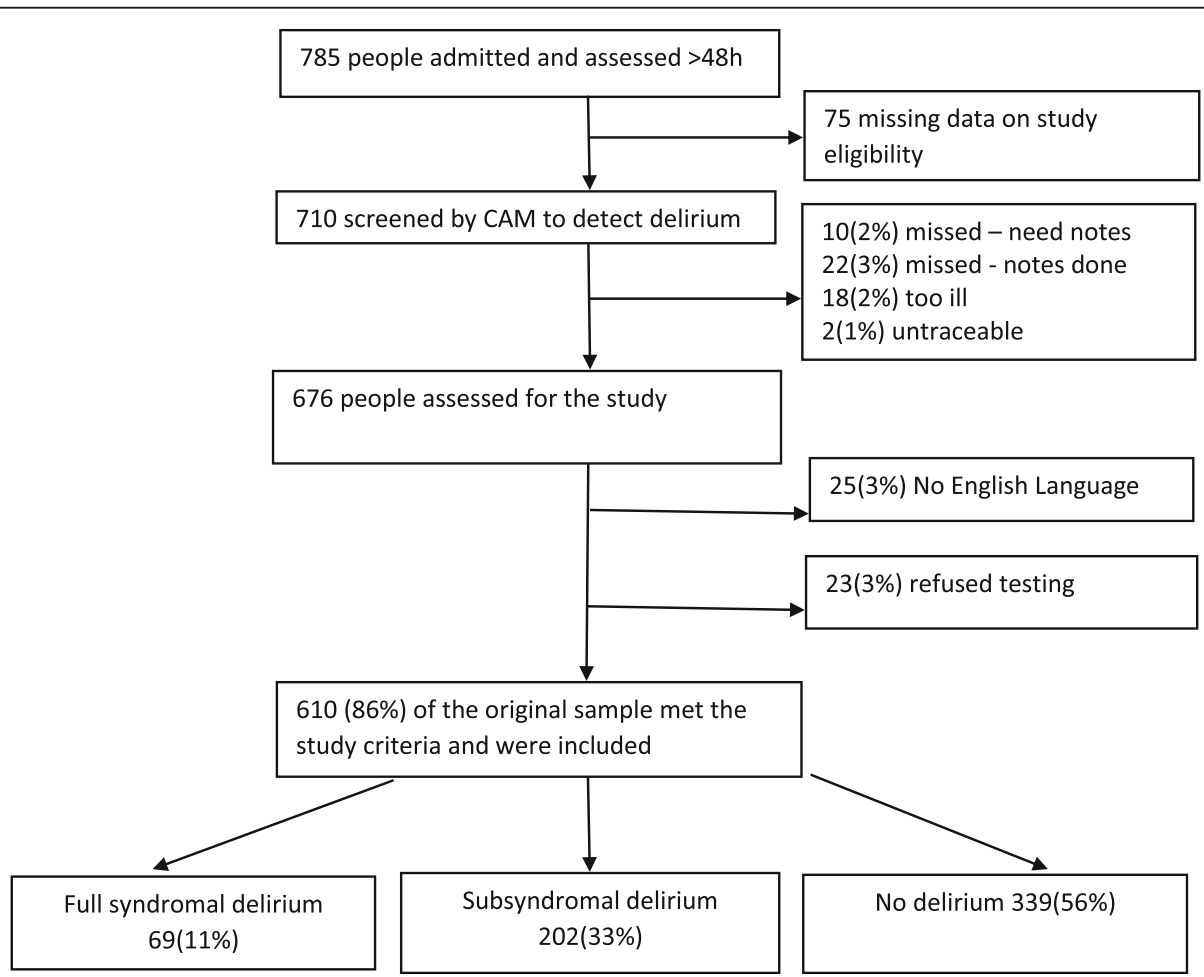

Fig. 1 Study flowchart. Study flowchart showing the exclusion process and exclusion criteria for the study sample. Eighty-six percent of the original sample were considered eligible for the study 
Table 1 Cohort characteristics by CAM delirium diagnosis

\begin{tabular}{|c|c|c|c|c|c|}
\hline \multirow{2}{*}{$\begin{array}{l}\text { Variables } n(\%), m(\mathrm{sd}), \\
\text { median (IQR) }\end{array}$} & \multirow[t]{2}{*}{ Total } & \multicolumn{3}{|c|}{ CAM delirium status } & \multirow[t]{2}{*}{$p$ value* } \\
\hline & & FSD & SSD & No delirium & \\
\hline$n,(\%)$ & $\begin{array}{l}610 \\
(100)\end{array}$ & $69(11)$ & $202(33)$ & $339(56)$ & \\
\hline
\end{tabular}

Demographics

Gender, (\%)

Male

Female

$251(41) \quad 24(10) \quad 70(28) \quad 157(62)$

Age in years, (\%)

70-79

80-89

$90+$

Type of residence, (\%)

House

Residential

Nursing home

Sheltered

Ethnicity, (\%)

White

$359(59) \quad 45(12) \quad 132(37) \quad 182(51)$

Marital status, (\%)

Married

Single

Widowed

Divorced

Unknown

Smoking status, (\%)

Never

Ex

Current

Unknown

Clinical Characteristics

Presence of CAM

individual item acute

onset, (\%) ${ }^{\mathrm{a}}$

Presence of CAM

individual item

inattention, $(\%)^{\mathrm{a}}$

Presence of CAM

individual item

disorganized

thinking, $(\%)^{\mathrm{a}}$

Presence of CAM

individual item,

altered level of

consciousness, (\%) ${ }^{\mathrm{a}}$

Psychiatric history admissions, $(\%)^{a}$

$\begin{array}{lllll}\text { None known } & 483(80) & 47(10) & 149(31) & 287(59) \\ \text { Anxiety } & 6(1) & 0(0) & 3(50) & 3(50) \\ \text { Depression and anxiety } & 12(2) & 2(17) & 5(42) & 5(42) \\ \text { Depression } & 86(14) & 17(20) & 37(43) & 32(37) \\ \text { Alcohol } & 9(1) & 1(11) & 4(44) & 4(44) \\ \text { Bipolar } & 3(1) & 0(0) & 1(33) & 2(67) \\ \text { Psychosis } & 8(1) & 2(25) & 3(37) & 3(38)\end{array}$

Table 1 Cohort characteristics by CAM delirium diagnosis (Continued)

\begin{tabular}{|c|c|c|c|c|c|}
\hline \multirow{2}{*}{$\begin{array}{l}\text { Variables } n(\%), m(\mathrm{sd}) \\
\text { median (IQR) }\end{array}$} & \multirow[t]{2}{*}{ Total } & \multicolumn{3}{|c|}{ CAM delirium status } & \multirow[t]{2}{*}{$p$ value $^{*}$} \\
\hline & & FSD & SSD & No delirium & \\
\hline \multicolumn{6}{|l|}{ Dementia status, (\%) } \\
\hline Yes & $159(26)$ & $45(28)$ & $84(53)$ & $30(19)$ & \multirow[t]{2}{*}{$<0.001^{*}$} \\
\hline No & $451(74)$ & $24(5)$ & $118(26)$ & $309(69)$ & \\
\hline \multicolumn{6}{|l|}{$\begin{array}{l}\text { Functional Assessment } \\
\text { Staging Score, (\%) }\end{array}$} \\
\hline $\begin{array}{l}\text { 1. No functional } \\
\text { impairment }\end{array}$ & $263(43)$ & $3(1)$ & $35(13)$ & $225(86)$ & \multirow[t]{5}{*}{$<0.001^{*}$} \\
\hline $\begin{array}{l}\text { 2-5. Subjective functional } \\
\text { deficit, objective } \\
\text { functional deficit, } \\
\text { difficulties with } \\
\text { activities of daily } \\
\text { living }\end{array}$ & $179(29)$ & $13(7)$ & $74(41)$ & $92(51)$ & \\
\hline $\begin{array}{l}\text { 6a-c. Help required getting } \\
\text { dressed, toileting or } \\
\text { personal hygiene }\end{array}$ & $66(11)$ & $24(36)$ & $29(44)$ & $13(20)$ & \\
\hline 6d-e. Double incontinence & $62(10)$ & $20(32)$ & $36(58)$ & $6(10)$ & \\
\hline $\begin{array}{l}\text { 7a-f. Speaks limited } \\
\text { vocabulary, can no } \\
\text { longer walk, sit up, } \\
\text { hold up head }\end{array}$ & $40(7)$ & $9(23)$ & $28(70)$ & $3(7)$ & \\
\hline $\begin{array}{l}\text { Waterlow score, } \\
\text { mean }(\mathrm{sd})^{\mathrm{a}} \mathrm{N}=605\end{array}$ & $13(6)$ & $17(7)$ & $15(7)$ & $11(5)$ & $<0.001^{*}$ \\
\hline \multicolumn{6}{|l|}{ Incontinence, $(\%)^{\mathrm{a}}$} \\
\hline None & $460(75)$ & $32(7)$ & $120(26)$ & $308(67)$ & \multirow[t]{4}{*}{$<0.001^{*}$} \\
\hline Urine & $58(10)$ & $14(24)$ & $28(48)$ & $16(28)$ & \\
\hline ICD on admission & $16(3)$ & $4(25)$ & $6(38)$ & $6(37)$ & \\
\hline Double & $75(12)$ & $19(25)$ & $48(64)$ & $8(11)$ & \\
\hline \multicolumn{6}{|l|}{ Pressure sores, (\%) } \\
\hline Yes & $58(10)$ & $14(24)$ & $36(62)$ & $8(14)$ & \multirow[t]{3}{*}{$<0.001^{*}$} \\
\hline No & $551(90)$ & $55(10)$ & $166(30)$ & $330(60)$ & \\
\hline Unknown & $1(0)$ & $0(0)$ & $0(0)$ & $1(100)$ & \\
\hline $\begin{array}{l}\text { Charlson Comorbidity } \\
\text { Index score, median (IQR) }\end{array}$ & $2(3)$ & $3(2)$ & $3(2)$ & $2(3)$ & 0.067 \\
\hline $\begin{array}{l}\text { APACHE II score, median } \\
(\mathrm{IQR})^{\mathrm{a}} \mathrm{N}=593\end{array}$ & $11(4)$ & $14(5)$ & $12(4)$ & $11(4)$ & $<0.001^{*}$ \\
\hline \multicolumn{6}{|c|}{ Commonest diagnosis on admission, (\%) } \\
\hline ACS & $56(9)$ & $3(5)$ & $10(18)$ & $43(77)$ & \multirow[t]{5}{*}{$<0.001^{*}$} \\
\hline COPD & $37(6)$ & $2(5)$ & $9(24)$ & $26(70)$ & \\
\hline UTI & $54(9)$ & $11(20)$ & $24(44)$ & 19 (35) & \\
\hline Pneumonia & $91(15)$ & $20(22)$ & $42(46)$ & $29(32)$ & \\
\hline Other & $372(61)$ & $33(9)$ & $117(31)$ & $222(60)$ & \\
\hline $\begin{array}{l}\text { Length of admission, } \\
\text { median }(\mathrm{QQR})^{\mathrm{a}} \mathrm{N}=609\end{array}$ & $8(13)$ & $14(20)$ & $9(13)$ & $7(10)$ & $<0.001^{*}$ \\
\hline $\begin{array}{l}\text { Survival time }- \text { days, } \\
\text { median }(\mathrm{IQR})^{\mathrm{a}} N=357\end{array}$ & $\begin{array}{l}157 \\
(457)\end{array}$ & $\begin{array}{l}125 \\
(355)\end{array}$ & $\begin{array}{l}143 \\
(454)\end{array}$ & 194 (495) & $0.022^{*}$ \\
\hline
\end{tabular}

Cohort characteristics stratified by delirium status: full syndromal delirium, subsyndromal delirium and no delirium. Count and percentage was calculated for categorical variables, mean and standard deviation was calculated for continuous variables normally distributed, and median and interquartile range was calculated for continuous variables with skewed distribution. Pearson Chi square, Analysis of Variance and Kruskal Wallis were used where appropriate. Significance level was set at $<0.05$ $s d$ standard deviation, $n$ number of participants, IQR interquartile range, * ${ }^{\text {significant, }}{ }^{a}$ complete case analysis, ACS Acute Cardiac Syndrome, COPD chronic obstructive pulmonary disease, UTI urinary tract infection, APACHE II Acute

Physiology and Chronic Health Evaluation II 


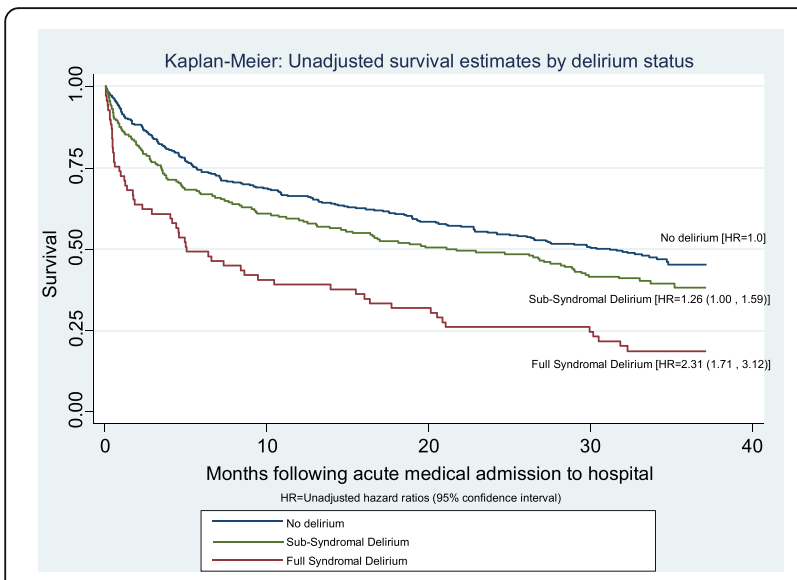

Fig. 2 Kaplan-Meier: Unadjusted survival estimates by delirium status. Kaplan Meier curves illustrate unadjusted survival estimates by delirium status. Full syndromal delirium is shown to have significant reduction in survival estimates, compared to patients no symptoms. It also shows that subsyndromal delirium has intermediate reduction in survival estimates compared against full syndromal delirium and no symptoms

a median survival time of 5 months, compared to 21 months for SSD and 31 months for participants with no symptoms (Table 2).

In unadjusted Cox models, participants with FSD had a higher mortality risk (HR 2.31 95\%CI 1.71, 3.12) compared with participants with no delirium. Participants with SSD had 1.26 (95\% CI 1.00, 1.59) greater risk of mortality compared to participants with no symptoms. Each adjustment variable (age, gender, CCI, Waterlow and APACHE II) was independently related to death $(p<0.001)$, except gender $(p=0.684)$. Sequential adjustment showed that the associations between FSD and mortality remained after adjusting for age, sex, CCI, Waterlow and APACHE II (HR 1.55 95\% CI 1.10, 2.18). The same sequence of adjustments for SSD and mortality showed greater attenuation $(\mathrm{HR}=0.9295 \% \mathrm{CI} 0.70,1.19)$.

Table 2 Mortality by delirium status $(95 \% \mathrm{Cl})$

\begin{tabular}{clll}
\hline & Delirium status & \\
\cline { 2 - 4 } & $\begin{array}{l}\text { Full delirium } \\
n=56\end{array}$ & $\begin{array}{l}\text { Subsyndromal } \\
\text { delirium } n=122\end{array}$ & $\begin{array}{l}\text { No delirium } \\
n=179\end{array}$ \\
\hline $\begin{array}{c}\text { Survival time\% } \\
<6 \text { months }\end{array}$ & $62.50(0.49,0.76)$ & $54.92(0.46,0.64)$ & $49.72(0.42,0.57)$ \\
$>6$ months & $37.50(0.24,0.51)$ & $45.08(0.36,0.54)$ & $50.28(0.43,0.58)$ \\
$\begin{array}{c}\text { Median survival } \\
\text { time (months) }\end{array}$ & $5.03(2.30,13.93)$ & $21.16(13.11,29.04)$ & $31.21(23.66, N A)$ \\
\hline
\end{tabular}

Percentage of eligible patients and $95 \%$ confidence intervals stratified into survival time less than or more than 6 months following hospital admission. Death was flagged by the UK Office of National Statistics and certified by a death certificate. Median length and $95 \%$ confidence intervals for survival time was calculated following hospital admission. Complete case $=357$ $<$, less than; $>$, more than; $N A$ not available
Unadjusted Cox models showed each s-CAM item was associated with higher mortality $(p<0.001)$.

After sequential adjustment for age, sex, CCI, Waterlow and APACHE II, acute onset (HR 1.41 95\% CI 1.07, 1.86) and disorganised thinking (HR $1.4295 \%$ CI $1.05,1.92)$ were associated with mortality, whereas this was no longer the case for estimates for inattention (HR 1.24 95\% CI 0.92, 1.67) and altered level of consciousness (HR 1.33 95\% CI $0.98,1.79)$. C-statistics for all models were very close (0.66 to 0.67 ), suggesting comparable predictive ability for this set of variables (Table 3 ).

\section{Discussion}

We demonstrated a dose-response relationship between SSD, FSD and mortality, even after adjustment for a wide range of acute and chronic health factors. Individual s-CAM items contribute differentially to this relationship; acute onset and disorganised thinking appear to drive the association. Taken together, these findings emphasise that neurocognitive symptoms that arise in the context of acute illness in older people identified individuals at higher risk for dying.

This study had several strengths. The large cohort size and prospective data in a diverse socio-economic and ethnic population benefited from standardised assessments by experts and automatic notification of deaths from the UK Office of National Statistics. Data was collected within a $72 \mathrm{~h}$ time-period after admission so it is not possible to establish whether cases of delirium were prevalent or incident and although the s-CAM has been shown to have good interrater reliability of $0.81-1.00$ [32] we do not have data on this for our study. In keeping with other studies, limitations include the possibility of residual confounding. We identified FSD and SSD at a prevalence and associated with adverse outcomes consistent with the range established from systematic reviews [1,2].

Participants with SSD had outcomes intermediate to those with no delirium and FSD - particularly in relation to acute illness severity, poor prognosis and outcomes, suggesting a dose-response relationship between delirium severity and mortality risk, which is in keeping with previous work $[19,21]$. However, few other studies have been able to establish these associations while also accounting for a wide range of acute and chronic health factors.

There is little literature exploring the individual mortality risk associated with each key symptom of delirium. We found each individual item on the short s-CAM was significantly associated with mortality, though acute onset and disorganised thinking had 
Table 3 Adjusted cox regression model for the effect of the four core symptoms of delirium status on mortality, sequentially adjusted for clinically relevant covariates

\begin{tabular}{|c|c|c|c|c|c|c|}
\hline \multicolumn{7}{|l|}{ HR (95\% Cl) p-value. } \\
\hline & None (unadjusted) & + Age & + Gender & $+\mathrm{CCl}$ & + Waterlow & + APACHE ॥ \\
\hline \multicolumn{7}{|l|}{ Delirium key core symptoms } \\
\hline \multirow[t]{3}{*}{ Acute onset $(n=583)$} & 1.88 & 1.80 & 1.80 & 1.76 & 1.46 & 1.41 \\
\hline & $(1.45,2.42)$ & $(1.39,2.33)$ & $(1.39,2.33)$ & $(1.35,2.29)$ & $(1.11,1.91)$ & $(1.07,1.86)$ \\
\hline & $p<0.001^{*}$ & $p<0.001^{*}$ & $p<0.001^{*}$ & $p<0.001^{*}$ & $p=0.007^{*}$ & $p=0.016^{*}$ \\
\hline \multirow[t]{3}{*}{ Inattention $(n=576)$} & 1.80 & 1.74 & 1.75 & 1.73 & 1.33 & 1.24 \\
\hline & $(1.40,2.32)$ & $(1.35,2.25)$ & $(1.36,2.26)$ & $(1.34,2.24)$ & $(1.01,1.77)$ & $(0.92,1.67)$ \\
\hline & $p<0.001^{*}$ & $p<0.001^{*}$ & $p<0.001^{*}$ & $p<0.001^{*}$ & $p=0.044^{*}$ & $p=0.152$ \\
\hline \multirow[t]{3}{*}{ Disorganised thinking $(n=563)$} & 2.06 & 1.97 & 2.01 & 1.94 & 1.52 & 1.42 \\
\hline & $(1.59,2.67)$ & $(1.51,2.55)$ & $(1.54,2.54)$ & $(1,48,2.54)$ & $(1.14,2.04)$ & $(1.05,1.92)$ \\
\hline & $p<0.001^{*}$ & $p<0.001^{*}$ & $p<0.001^{*}$ & $p<0.001^{*}$ & $p=0.005^{*}$ & $p=0.024^{*}$ \\
\hline \multirow[t]{3}{*}{ Altered level of consciousness $(n=588)$} & 2.04 & 1.95 & 1.96 & 1.82 & 1.41 & 1.33 \\
\hline & $(1.58,2.63)$ & $(1.50,2.52)$ & $(1.51,2.53)$ & $(1.40,2.37)$ & $(1.06,1.88)$ & $(0.98,1.79)$ \\
\hline & $p<0.001^{*}$ & $p<0.001^{*}$ & $p<0.001^{*}$ & $p<0.001^{*}$ & $p=0.018^{*}$ & $p=0.063$ \\
\hline
\end{tabular}

Cox proportional hazard regression analysis for survival estimates for the four key core symptoms of full syndromal delirium. Unadjusted model complete case $=610$. The same sample was used for the sequentially adjusted Cox proportional hazards regression model (age, gender, CCI, Waterlow and APACHE II). APACHE II and CCI scores were split into quartiles for the purpose of the analysis. There was no evidence of interactions, these, therefore were no longer considered. Proportional hazard assumptions were met, confirmed by Schoenfeld residuals $\geq 0.05$. Significance level set at $<0.05$

CAM Confusion Assessment Method, $H R$ hazard ratios, $\mathrm{Cl}$ confidence intervals, $p$ significance level, $N$ number of participants, * significant, $C C l$ Charlson Comorbidity Index, APACHE II Acute Physiology and Chronic Health Evaluation II

greater risk of mortality when all items were mutually adjusted.

A number of underlying mechanisms may explain the observed dose-response relationship between delirium and mortality. The causes of delirium can persist, which itself could lead to protracted delirium, prolonged hospital stays [15], and increased risk of death [33]. In turn, longer hospital stays could expose patients to a greater risk of iatrogenic harm $[34,35]$ for example: participants with hypoactive delirium have a greater risk of aspiration pneumonia, whereas participants with hyperactive delirium have greater risk of falls [36, 37] which in turn could cause longer hospital stays, further health deterioration and greater risk of death. Disorganised thinking could be a particularly adverse symptom because it may represent more profound neurocognitive disturbance particularly detrimental in frail, older participants predisposed to chronic and severe physical illness [3, 38-40].

\section{Conclusions}

Emergency admission of an older patient presenting with FSD or SSD is a strong potential indicator of risk of death. Clinically it is important to be aware that each key symptom of FSD is strongly related to death, and participants presenting with just one symptom still carry an increased risk - highlighting the necessity of recognising each symptom separately. Better awareness of the mortality risk associated with delirium would strengthen arguments for early intervention, better treatment and quality of care, considering care plans and encouragement of discussion of prognosis with the patient and/or carer.

\section{Abbreviations}

ANOVA: Analysis of Variance; APACHE II: Acute Physiology and Chronic Health Evaluation; CAM: Confusion Assessment Method; CCl: Charlson Comorbidity Index; DSM: Diagnostic and Statistical Manual of Mental Disorders; FAST: Functional Assessment Staging; FSD: Full syndromal delirium; HR: Hazard ratio; IQR: Interquartile range; ONS: Office for National Statistics; S-CAM: Short Confusion Assessment Method-short version; sd: standard deviation; SSD: Subsyndromal delirium

\section{Acknowledgements}

Not applicable

\section{Funding}

The study the dataset originated from (Sampson et al., [22]) was funded by the Medical Research Council (GB) Special Training Fellowship in Health Services Research (G106/1177). DD is funded through a Wellcome Trust Intermediate Clinical Fellowship (WT107467). ELS and W are supported by Marie Curie core grant funding to the Marie Curie Palliative Care Research Department at University College London, grant MCCC-FCO-16-U.Funding bodies played no role in the design of the study, data collection, analysis, and interpretation of the data and in writing the manuscript.

\section{Availability of data and materials}

The datasets used and/or analysed during the current study available from the corresponding author on reasonable request. 


\section{Authors' contributions}

ELS conducted the original study. RAD, W and DD planned the data analysis. RAD analysed and interpreted data. ELS, DD and $W$ assisted with interpretation of the data outcomes. All authors contributed to the writing of the manuscript and approved the final manuscript.

\section{Ethics approval and consent to participate}

The study was approved by the Royal Free Hospital NHS Ethics Committee (06/Q0501/31). This included the procedure for verbal consent for the original data collection, which was allowed, at the time, because this was an observational study using measures routinely collected in clinical practice. Data was de-identified before we received it and used it for this analysis.

\section{Consent for publication}

Not applicable.

\section{Competing interests}

The authors declare that they have no competing interests.

\section{Publisher's Note}

Springer Nature remains neutral with regard to jurisdictional claims in published maps and institutional affiliations.

\section{Author details}

${ }^{1}$ Marie Curie Palliative Care Research Department, Division of Psychiatry, Faculty of Brain Sciences, University College London, Gower Street, London WC1E 6BT, UK. ${ }^{2} \mathrm{MRC}$ Unit for Lifelong Health and Ageing at UCL, 33 Bedford Place, London WC1B 5JU, UK. ${ }^{3}$ The Research Department of Primary Care and Population Health, UCL, Rowland Hill Street, London NW3 2PF, UK. ${ }^{4}$ Barnet Enfield and Haringey Mental Health Trust Liaison Psychiatry Team, North Middlesex University Hospital, London N18 1QX, UK.

Received: 13 September 2017 Accepted: 16 January 2018

Published online: 25 January 2018

\section{References}

1. Siddiqi N, House AO, Holmes JD. Occurrence and outcome of delirium in medical in-patients: a systematic literature review. Age Ageing. 2006;35(4): 350-64

2. Ouimet S, Kavanagh BP, Gottfried SB, Skrobik Y. Incidence, risk factors and consequences of ICU delirium. Intensive Care Med. 2007;33(1):66-73.

3. Witlox J, Eurelings LS, de Jonghe JF, Kalisvaart KJ, Eikelenboom P, van Gool WA. Delirium in elderly patients and the risk of postdischarge mortality, institutionalization, and dementia: a meta-analysis. JAMA. 2010;304(4):443-51.

4. Collins N, Blanchard MR, Tookman A, Sampson EL. Detection of delirium in the acute hospital. Age Ageing. 2010;39(1):131-5.

5. American Psychiatric Association. Diagnostic and statistical manual of mental disorders. 4th ed. Washington DC: American Psychiatric Association: 1994

6. Leslie DL, Zhang Y, Holford TR, Bogardus ST, Leo-Summers LS, Inouye SK. Premature death associated with delirium at 1-year follow-up. Arch Intern Med. 2005;165(14):1657-62

7. Fong TG, Davis D, Growdon ME, Albuquerque A, Inouye SK. The interface between delirium and dementia in elderly adults. Lancet Neurol. 2015;14(8): 823-32.

8. Ward G, Perera G, Stewart R. Predictors of mortality for people aged over 65 years receiving mental health care for delirium in a South London Mental Health Trust, UK: a retrospective survival analysis. Int J Geriatr Psychiatry. 2015;30(6):639-46

9. Inouye SK, van Dyck CH, Alessi CA, Balkin S, Siegal AP, Horwitz Rl. Clarifying confusion: the confusion assessment method. A new method for detection of delirium. Ann Intern Med. 1990;113(12):941-8.

10. Sepulveda E, Franco JG, Trzepacz PT, Gaviria AM, Meagher DJ, Palma J, Vinuelas E, Grau I, Vilella E, de Pablo J. Delirium diagnosis defined by cluster analysis of symptoms versus diagnosis by DSM and ICD criteria: diagnostic accuracy study. BMC Psychiatry. 2016;16:167

11. Dasgupta M, Dumbrell AC. Preoperative risk assessment for delirium after noncardiac surgery: a systematic review. J Am Geriatr Soc. 2006;54(10):1578-89.

12. Morandi A, Jackson JC, Ely EW. Delirium in the intensive care unit. Int Rev Psychiatry. 2009;21(1):43-58.
13. Cole MG. Persistent delirium in older hospital patients. Curr Opin Psychiatry. 2010;23(3):250-4.

14. Davis DH, Muniz-Terrera G, Keage HA, Stephan BC, Fleming J, Ince PG, Matthews FE, Cunningham C, Ely EW, MacLullich AM, et al. Association of delirium with cognitive decline in late life: a neuropathologic study of 3 population-based cohort studies. JAMA Psychiatry. 2017;74(3):244-51

15. Kiely DK, Marcantonio ER, Inouye SK, Shaffer ML, Bergmann MA, Yang FM, Fearing MA, Jones RN. Persistent delirium predicts greater mortality. J Am Geriatr Soc. 2009;57(1):55-61.

16. Inouye SK, Rushing JT, Foreman MD, Palmer RM, Pompei P. Does delirium contribute to poor hospital outcomes? A three-site epidemiologic study. J Gen Intern Med. 1998;13(4):234-42.

17. Salluh Jl, Wang H, Schneider EB, Nagaraja N, Yenokyan G, Damluji A, Serafim RB, Stevens RD. Outcome of delirium in critically ill patients: systematic review and meta-analysis. BMJ. 2015;350:h2538.

18. Lindesay J, Rockwood K, Rolfson D. The epidemiology of delirium. In: Lindesay J, Rockwood K, Macdonald A, editors. Delirium in Old Age. Oxford: Oxford University Press; 2002. p. 27-50.

19. Cole MG, Ciampi A, Belzile E, Dubuc-Sarrasin M. Subsyndromal delirium in older people: a systematic review of frequency, risk factors, course and outcomes. Int J Geriatr Psychiatry. 2013;28(8):771-80.

20. Ouimet S, Riker R, Bergeron N, Cossette M, Kavanagh B, Skrobik Y. Subsyndromal delirium in the ICU: evidence for a disease spectrum. Intensive Care Med. 2007;33(6):1007-13.

21. Marcantonio ER, Kiely DK, Simon SE, John Orav E, Jones RN, Murphy KM, Bergmann MA. Outcomes of older people admitted to postacute facilities with delirium. J Am Geriatr Soc. 2005:53(6):963-9.

22. Sampson EL, Blanchard MR, Jones L, Tookman A, King M. Dementia in the acute hospital: prospective cohort study of prevalence and mortality. $\mathrm{Br}$ J Psychiatry. 2009;195(1):61-6.

23. Inouye SK. The Short Confusion Assessment Method (Short CAM): training manual and coding guide. Boston: Hospital Elder Life Program; 2014.

24. van Velthuijsen EL, Zwakhalen SM, Warnier RM, Mulder WJ, Verhey FR, Kempen Gl. Psychometric properties and feasibility of instruments for the detection of delirium in older hospitalized patients: a systematic review. Int J Geriatr Psychiatry. 2016;31(9):974-89.

25. Charlson ME, Pompei $P$, Ales KL, MacKenzie CR. A new method of classifying prognostic comorbidity in longitudinal studies: development and validation. J Chronic Dis. 1987:40(5):373-83.

26. Charlson M, Szatrowski TP, Peterson J, Gold J. Validation of a combined comorbidity index. J Clin Epidemiol. 1994;47(11):1245-51.

27. Waterlow J. Pressure sores: a risk assessment card. Nurs Times. 1985; 81(48):49-55.

28. Knaus WA, Draper EA, Wagner DP, Zimmerman JE. APACHE II: a severity of disease classification system. Crit Care Med. 1985;13(10):818-29.

29. Adamis D, Treloar A, Darwiche FZ, Gregson N, Macdonald AJ, Martin FC. Associations of delirium with in-hospital and in 6-months mortality in elderly medical inpatients. Age Ageing. 2007:36(6):644-9.

30. Man SY, Chan KM, Wong FY, Wong KY, Yim CL, Mak PS, Kam CW, Lau CC, Lau FL, Graham CA, et al. Evaluation of the performance of a modified Acute Physiology and Chronic Health Evaluation (APACHE II) scoring system for critically ill patients in emergency departments in Hong Kong. Resuscitation. 2007;74(2):259-65.

31. Reisberg B, Sclan SG, Franssen E, Kluger A, Ferris S. Dementia staging in chronic care populations. Alzheimer Dis Assoc Disord. 1994;8(Suppl 1): S188-205.

32. Wei LA, Fearing MA, Sternberg EJ, Inouye SK. The Confusion Assessment Method: a systematic review of current usage. J Am Geriatr Soc. 2008;56(5): 823-30.

33. Shehabi Y, Riker RR, Bokesch PM, Wisemandle W, Shintani A, Ely EW, Group SS. Delirium duration and mortality in lightly sedated, mechanically ventilated intensive care patients. Crit Care Med. 2010;38(12):2311-8

34. O'Keeffe S, Lavan J. The prognostic significance of delirium in older hospital patients. J Am Geriatr Soc. 1997;45(2):174-8

35. Permpongkosol S. latrogenic disease in the elderly: risk factors, consequences, and prevention. Clin Interv Aging. 2011;6:77-82

36. Lakatos BE, Capasso V Mitchell MT, Kilroy SM, Lussier-Cushing M, Sumner L Repper-Delisi J, Kelleher EP, Delisle LA, Cruz C, et al. Falls in the general hospital: association with delirium, advanced age, and specific surgical procedures. Psychosomatics. 2009;50(3):218-26. 
37. Marcantonio E, Ta T, Duthie E, Resnick NM. Delirium severity and psychomotor types: their relationship with outcomes after hip fracture repair. J Am Geriatr Soc. 2002;50(5):850-7.

38. Maclullich AM, Ferguson KJ, Miller T, de Rooij SE, Cunningham C. Unravelling the pathophysiology of delirium: a focus on the role of aberrant stress responses. J Psychosom Res. 2008;65(3):229-38.

39. van Gool WA, van de Beek D, Eikelenboom P. Systemic infection and delirium: when cytokines and acetylcholine collide. Lancet. 2010; 375(9716):773-5.

40. Dani M, Owen LH, Jackson TA, Rockwood K, Sampson EL, Davis D. Delirium, frailty and mortality: interactions in a prospective study of hospitalized older people. J Gerontol A Biol Sci Med Sci. 2017. https:/doi.org/10.1093/gerona/gl×214.

Submit your next manuscript to BioMed Central and we will help you at every step:

- We accept pre-submission inquiries

- Our selector tool helps you to find the most relevant journal

- We provide round the clock customer support

- Convenient online submission

- Thorough peer review

- Inclusion in PubMed and all major indexing services

- Maximum visibility for your research

Submit your manuscript at www.biomedcentral.com/submit
Biomed Central 